\title{
Chronic urticaria merits serum vitamin D evaluation and supplementation; a randomized case control study
}

\author{
Roohi Rasool ${ }^{1^{*}}$, Khalid Z Masoodi ${ }^{2}$, Irfan A Shera', Qayser Yosuf ${ }^{1}$, Imtiyaz A Bhat ${ }^{1}$, Iqbal Qasim', Saniya Nissar ${ }^{1}$ \\ and Zafar A Shah ${ }^{1}$
}

\begin{abstract}
Background: Several studies suggest that Vitamin D (Vit- $D_{3}$ ) supplementation reduces Chronic Urticaria (CU) symptoms. Objectives: Evaluation of serum 25-hydroxyvitamin-D (25 $\left.(\mathrm{OH})_{2} \mathrm{D}\right)$ level and assessment of therapeutic effect of VitD $\mathrm{in}_{3}$ CU patients.

Methods: 192 subjects were stratified according to the baseline $25(\mathrm{OH})_{2} \mathrm{D}$ levels and subsequently randomized into three subgroups to receive Vit- $\mathrm{D}_{3}$ alone $(\mathrm{VD})$ or antihistamine and systemic corticosteroid $(\mathrm{H}+\mathrm{S})$ or $\mathrm{Vit}_{3}$ with antihistamine and systemic corticosteroid (VD+H+S) for 6 weeks between July 2012 to Oct 2014. 130 healthy controls (HC) were followed without any intervention. The patients were evaluated for reduction in urticarial symptoms using visual analogue scale (VAS) and 5-D itch score.
\end{abstract}

Results: Low serum levels of $25(\mathrm{OH})_{2} \mathrm{D}$ was observed in $91 \%$ of $\mathrm{CU}$ patients and $64 \%$ of the healthy controls $(\mathrm{P}<0.0001)$. VAS and 5-D Score in subgroups VD, H+S and VD $+H+S$ decreased significantly from $6 \cdot 7 \pm 0 \cdot 043,6 \cdot 6 \pm 0 \cdot 42$ and $6 \cdot 68 \pm 0 \cdot 40$ at baseline to $5 \cdot 2 \pm 0 \cdot 70(P=0 \cdot 0088), 3 \cdot 3 \pm 0 \cdot 50(P<0 \cdot 0001)$ and $1 \cdot 86 \pm 0 \cdot 39(P<0 \cdot 0001)$ after treatment and from $14 \cdot 5 \pm 0 \cdot 72,13 \cdot 9 \pm 0 \cdot 77$ and $13 \cdot 9 \pm 0 \cdot 221$ to $12 \cdot 06 \pm 1 \cdot 10(P=0 \cdot 0072), 8 \cdot 1 \pm 1 \cdot 13(P<0 \cdot 0001)$ and $5 \cdot 01 \pm 0 \cdot 94(P<0 \cdot 0001)$ respectively.

Conclusions: $\mathrm{CU}$ patients have low serum $25(\mathrm{OH})_{2} \mathrm{D}$ levels and Vit- $\mathrm{D}_{3}$ supplementation in combination with antihistamine and systemic corticosteroid show elevated response in resolving the symptoms of CU. This study also warrants that each subject with $\mathrm{CU}$ should be screened for serum $25(\mathrm{OH})_{2} \mathrm{D}$ levels before starting a treatment.

Keywords: $25(\mathrm{OH})$ vitamin D, 5-D itch score, Chronic Urticaria, Visual analogue scale, IgE

\section{Background}

$\mathrm{CU}$ is defined as the presence of evanescent wheals which reoccur for greater than 6 weeks[1]. CU is allergic skin dermatosis, and despite extensive evaluation for underlying causes or triggers, the etiology remains unclear[2]. CU is a common skin disease that is rarely life threatening, however the high incidence and prevalence make it a paramount public health problem, which has protracted course and can result in significant morbidity[3]. Antihistamines and systemic steroids form the basis of treatment, but response is often incomplete [4]. Although second-line therapies,

\footnotetext{
* Correspondence: roohi_wani@yahoo.com

'Department of Immunology and Molecular Medicine, Sher-i- Kashmir

Institute of Medical Sciences, Soura, Srinagar, J\&K 190011, India

Full list of author information is available at the end of the article
}

such as cyclosporine[5] and anti IgE therapy (omalizumab) [6], have been shown to be effective in randomized controlled trials, there are concerns about costs and adverse side effects associated with these therapies[7].

There are numerous studies suggesting potential role of Vit D in improving health outcomes, as far as allergic disorders are concerned. High prevalence of Vit D deficiency has also been reported in north Indian population[8]. Prevalence of atopic disorders in Vit D deficient patients when compared withVit D sufficient patients showed an increased risk of atopic dermatitis among those patients who were Vit D deficient. However, there was no significant difference in the risk of asthma or allergic rhinitis between Vit D deficient patients and Vit D sufficient patients[9]. Vit D deficiency has been shown to correlate

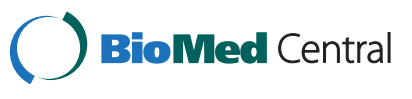

(c) 2015 Rasool et al.; licensee BioMed Central. This is an Open Access article distributed under the terms of the Creative Commons Attribution License (http://creativecommons.org/licenses/by/4.0), which permits unrestricted use, distribution, and reproduction in any medium, provided the original work is properly credited. The Creative Commons Public Domain Dedication waiver (http://creativecommons.org/publicdomain/zero/1.0/) applies to the data made available in this article unless otherwise stated. 
with many food and environmental allergies in children [10]. Conversely, other studies have shown an association between high Vit D levels and the development of allergic rhinitis[11].

Although the molecular mechanism underlining the relation between $\mathrm{CU}$ and Vit $\mathrm{D}$ is still unknown, Vit D has been shown to play a considerablerole in the immune responses generated by antigen-presenting cellsthat has been recognized with the discovery of Vit D receptors (VDRs) on these cells[12]. VDRs have been present on a variety of cells, including keratinocytes and numerous cells of immune system (e.g. T cells, B cells, neutrophils, macrophages, and dendritic cells) [13]. The scope of biological role of the action of Vit D through VDRs helped clarify the link between Vit D and immune functions[14]. Also, Vit D affects innate and adaptive immunity through the stimulation of Toll-like receptors, increasing pro-inflammatory cytokine production, and possibly enhancing $\mathrm{T}$ helper type 2 responses, thereby defining the possible association of Vit $\mathrm{D}$ to allergic disorders. Many reports suggest a possible influence of Vit $\mathrm{D}$ on prevalence of allergic diseases even though results are still conflicting [15].

Though there have beenfewer studies that have evaluated the potential link between Vit D and urticaria[16,17], we sought to determine whether a relationship between Vit $\mathrm{D}$ and $\mathrm{CU}$ exists.

Though there have been mixed reviews about the use of Vit D as treatment in CU,Vit D has been successfully used as a treatment modality in psoriasis and lupus vulgaris $[18,19]$. Skin lesions were resolved when Vit D insufficiency was treated with oral supplementation of Vit $D[20]$. Likewise no cutaneous consequences of low Vit D are described in Holick's extensive reviews of the health implications of Vit D deficiency and inadequacy [21]. Recently it has been determined that a high dose (4,000 IU/day) of Vit D3 is more beneficial than a low dose (600 IU/day) which can be used as an add-on therapy in CU patients. High dose of Vit D3 can be considered as safe in patients with $\mathrm{CU}[22]$.

In light of several conflicting hypotheses, we conducted a randomized controlled study to investigate the efficacy and therapeutic benefits of different treatment regimens with and without Vit $\mathrm{D}_{3}$ supplementation inCU patients.

\section{Methods}

\section{Study population}

Patients aged 18 to 60 years with a clinical diagnosis of moderate-to-severe CSU were evaluated in the present investigation. The criteria for CSU severity was assessed according to the classified consensus guidelines from the European Academy of Allergology and Clinical
Immunology [EAACI] and the World Allergy Organization [WAO] [23,24].

\section{Evaluation of the $\mathrm{CU}$ symptoms}

The 5-D itch scale is a multidimensional questionnaire designed to be useful as an outcome measure in clinical trials[25]. The five dimensions are;degree, duration, direction, disability and distribution of pruritus per 24 hours. The scores of each of the five domains are calculated separately and then summed together to obtain a total 5-D score. 5-D scores can potentially range between 5 (no pruritus) and 25 (most severe pruritus). Randomization was performed by using a validated system that automated the random assignment of the treatments to randomization numbers. The present investigation consisted of a pre-screening visit, a 4 week screening period and a 6 week treatment period and 4 weeks follow up. At the prescreening visit, informed consent was obtained, and patients were assessed for eligibility. VAS was used as a method of pruritis assessment in CSU patients[26].

\section{Inclusion criteria}

The patients with persistent symptoms for more than 6 weeks at screening, body weight between 25 and $100 \mathrm{~kg}$, a total serum IgE level ranging between $30 \mathrm{IU} / \mathrm{mL}$ to700 $\mathrm{IU} / \mathrm{mL}$, and a weekly 5 -D score of 10 or greater and visual activity score (VAS) of 5 or greater at the end of screening were eligible for enrollment in the study. Serum $25(\mathrm{OH})_{2} \mathrm{D}$ levels $<10 \mathrm{ng} / \mathrm{ml}$ reflect severe Vit D deficiency, levels between $10-20 \mathrm{ng} / \mathrm{ml}$ depicted as deficient, levels $20-30 \mathrm{ng} / \mathrm{ml}$ were described as insufficient and 25 $(\mathrm{OH})_{2} \mathrm{D}$ levels of $>30 \mathrm{ng} / \mathrm{ml}$ were defined as sufficient levels $[27,28]$.

\section{Exclusion criteria}

Patients having lesions that last more than 24 hours, and having physical urticaria syndromes were not included in this study. Patients were excluded if they had received antihistamines, systemic steroids or immunosuppressive therapy during the preceding 3 months. Patients that were having morbidity like diabetes, hypertension, dermatitis herpetiformis and mastocytoma and any form of kidney disease were also excluded. Patients having hypercalcemia or any other calcium disorders were also excluded from the study. Patients with urticaria caused by infection, food allergy and drug allergy were also excluded.

\section{Baseline investigations}

Baseline investigations in all patients included a routine laboratory tests like full blood count, erythrocyte sedimentation rate, urine analysis, serum glucose, hepatic functions and creatinine. Patients were also tested for hepatic serology, thyroid function test, antinuclear and anti-thyroid microsomal antibodies. Chest X-ray and 
abdominal ultrasound were also performed on the patients. The patients also underwent the detection for Helicobacter pylori. Autologous serum skin testing (ASST), skin prick test (SPT) were also performed on all patients.

\section{Safety assessment}

Safety assessment included the monitoring and recording the severity of adverse events, along with evaluation of their duration and relationship to the study. In addition, routine urine analysis, regular monitoring of hematology and blood chemistry results and assessment of vital signs and body weight were performed[24]. Patients were also monitored for calcium levels at week 2, 4 and 6 .

\section{Study design and treatment groups}

Measurement properties were analyzed using data from randomized, parallel- group study of orally administered Vit D as add-on therapy for the treatment of CSU. 505 patients and 210 normal matched healthy controls were assessed for eligibility and finallynarrowed down to 192 and 130 respectively from the outpatient department of Allergy/Immunology ofthe Sher-i-Kashmir Institute of
Medical Science,Srinagar,in the period between July 2012Oct 2014. The study was approved by the ethics committee of the institutionand was conducted in accordance with the International Conference on Harmonization Guidelines for Good Clinical Practice, the ethical principles embodied in the Declaration of Helsinki (1989), and applicable local regulations. Written informed consent was obtained from all patients before their participation in the study.

\section{Experimental design}

Subjects were initially divided into two groups, chronic urticaria (CU) and Healthy control (HC). 505 patients were initially screened for the study out of which $63.9 \%$ did not fulfill the eligibility criteria or refused to participate or had evidence of drug and/or alcohol abuse (Figure 1). Baseline serum Vit D was evaluated as 25-hydroxyvitamin D $\left(25(\mathrm{OH})_{2} \mathrm{D}\right)$ using enzyme immuno assay in all the subjects. $192 \mathrm{CU}$ patients fulfilling the eligibility criteria,were stratified into 4 Groups. Patients with serum levels $<10 \mathrm{ng} / \mathrm{ml}$ reflecting severe vitamin deficiency were included in group 1 . Patients having $10-20 \mathrm{ng} / \mathrm{ml}$ of serum $25(\mathrm{OH})_{2}$ D depicted deficient levels and were

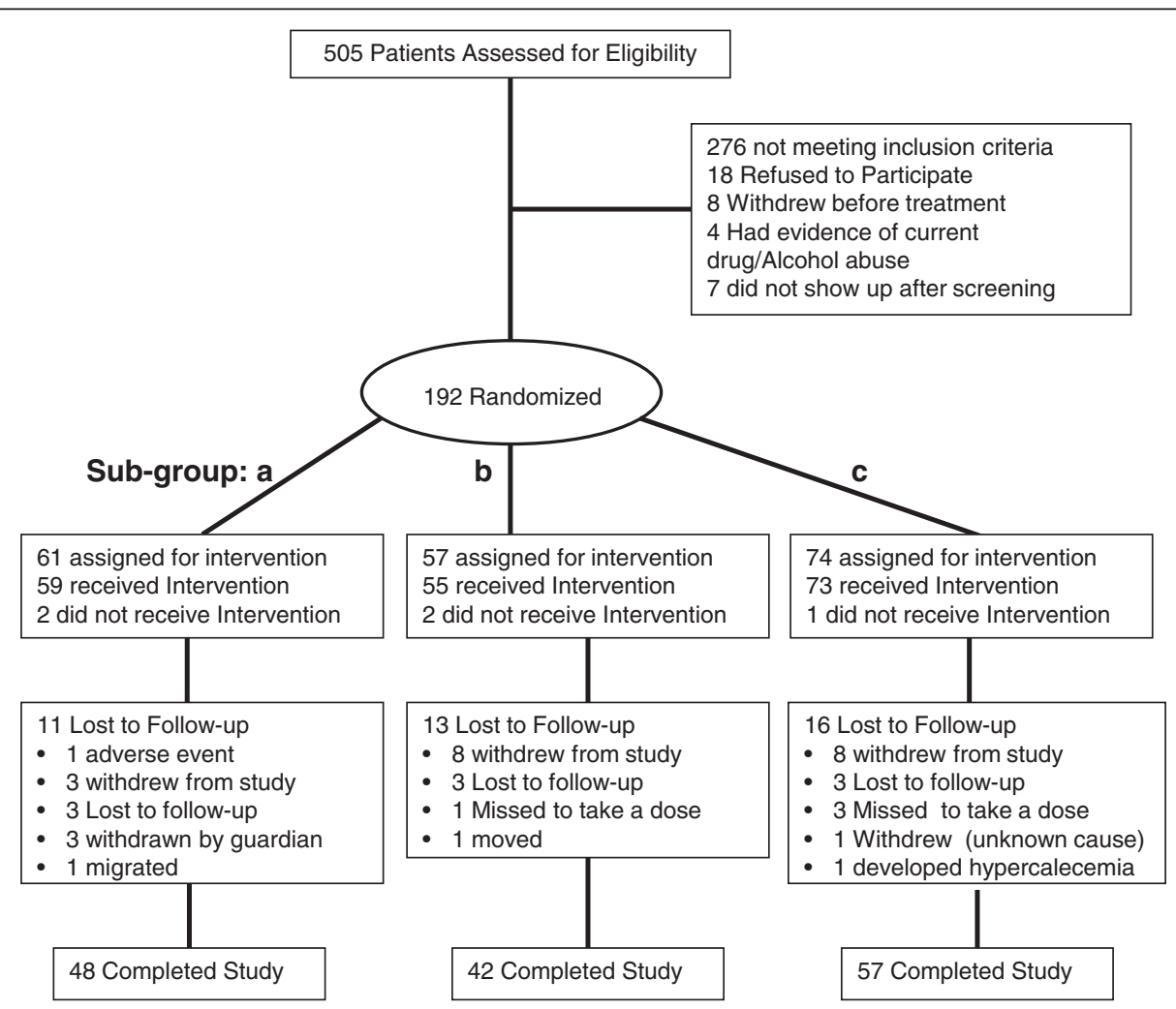

Figure 1 Enrollment and outcome. 505 patients were enrolled for eligibility out of which only 192 fulfilled the eligibility criteria. 276 patients did not fulfill the criteria, 18 patients refused to participate, 8 withdrew before treatment, 4 patients having evidence of current drug/alcohol abuse were not recruited for the study and 7 did not show up after screening. 192 patients fulfilling the eligibility criteria were randomized into groups $\mathbf{a}, \mathbf{b}$ and $\mathbf{c}$. 48 patients in group $\mathbf{a}, 42$ in group $\mathbf{b}$ and 57 in group c completed the study. The rest withdrew from study, had adverse events, missed to take the dose, were withdrawn by the guardian or were lost to follow-up. 
included into group 2 . The patients in which the level of $25(\mathrm{OH})_{2}$ D ranged between $20-30 \mathrm{ng} / \mathrm{ml}$ were described as insufficient and comprised group 3 and the patients where $25(\mathrm{OH})_{2} \mathrm{D}$ levels greater than 30 were defined as sufficient and comprised group 4. The four groups were then randomized and treated using three different protocols; a, b and c (Figure 2a).

The four groups were randomized into 3 subgroups a, $\mathrm{b}$ and c. Out of these, 48 in subgroup a, 42 in subgroup $\mathrm{b}$ and 57 in subgroup c completed the study (Figure 2a). The rest were lost to follow-up, had adverse events, were withdrawn by guardian, missed a dose or developed hypercalcemia (Figure 2b). The experimental design is outlined in Figure 2a \& b. All subjects satisfying entry criteria were randomized to receive three different treatment regimens.

In subgroup a (VD), 48patients received oral Vit $\mathrm{D}_{3}$ (cholecalciferol) sachets at a dose of 60,000 IU per week for 4 weeks.In subgroup b $(\mathrm{H}+\mathrm{S}), 42$ patients received, antihistamine (Hydroxyzine $25 \mathrm{mg}$ ) and corticosteroids (Deflazacort $6 \mathrm{mg}$ )PO daily for 6 weeks. In subgroup c (VD $+\mathrm{H}+\mathrm{S}$ ), 57 patients received combinatorial therapy with oral $\mathrm{VitD}_{3}$ sachets at a dose of 60,000 IU per week for 4 weeks, antihistamine PO, corticosteroids PO daily for 6 weeks. Healthy control group $(n=130)$ was followed as such without any intervention for 6 weeks as described in protocol d (HC) (Figure 2a). The patients were followed up to 10 weeks for safety assessment from the start of the treatment regimen to see if the patients had recurrence of symptoms or any other off target effects or any adverse after effects of the treatment.

\section{Monitoring and study end points}

Follow up visit was done at two, four and six weeks to assess the treatment efficacy for $\mathrm{CU}$ and any toxic effects of Vit D. At each visit, any adverse effects of treatment regimens were recorded. The mean reduction in 5-D score and VAS after 6 weeks of treatment compared with the baseline score signifies therapeutic response of treatment regimens in $\mathrm{CU}$.

Blood was collected at prescreening, at baseline, at week two, week four and week six after treatment from each subject of Subgroup a, b, c and d, to evaluate 25 $(\mathrm{OH})_{2}$ VitD levels and to ensure none exceeded moderate normal values.

\section{Statistical analysis}

The sample size was chosen to ensure $85 \%$ power for the primary end point, the mean weekly VAS and 5-D score, by using a 2-sided 5\% significance level to detect a treatment effect at least as large as its SD (standardized effect size, $>1$ ). Data was expressed as Mean \pm standard error mean (SEM). The difference in the mean values of Vit D in both the cases and control groups were analyzed by paired $t$-test to calculate the difference within groups and Bonferroni independent samples $t$-test was used to calculate the level of difference between groups. The primary end point (VAS and 5D-Score) was evaluated by using an analysis of covariance model with the factors of treatment and center and with the baseline score as the covariate. For the treatment contrast among the three subgroups a, b and c, a 95\% CI and a 2-sided P value were calculated. Mean score (VAS, 5-D) changes within subgroup a,b and c were compared, using paired $t$-test (keeping normality of the observation into considerations). Intergroup comparison at different time-points was done using analysis of variance test (ANOVA). A $P<0.05$ was taken to be statistically significant. Statistical analysis was performed using GraphPad Prism version 6.00 for Windows (GraphPad Software, San Diego California USA.

\section{Results}

\section{Demographics and vitamin D levels}

A total of $192 \mathrm{CU}$ patients were enrolled in the present investigation out of which only 147 were considered for the final evaluation (Figure 2). There was no significant difference in age of CU Patients (mean years \pm SD; 42 . $83 \pm 8 \cdot 52)$ vs controls $(45 \cdot 12 \pm 7 \cdot 65)$ and patients were predominantly female $(67 \cdot 7 \%) \cdot 18 \cdot 9 \%$ of patients were smokers and $25 \cdot 4 \%$ of the healthy control had been smoking over a year. Mean \pm SEM Vit D was $17 \cdot 87 \pm 1$. $22 \mathrm{ng} / \mathrm{ml}$ for subjects versus $27.65 \pm 1.65 \mathrm{ng} / \mathrm{ml}$ for controls.

Vit D deficiency or insufficiency was seen in $91.3 \%$ of the subjects with $\mathrm{CU}$ and $63 \cdot 84 \%$ of the healthy controls. Vit D levels were significantly lower $(\mathrm{P}<0 \cdot 0001)$ in subjects with CU compared with controls (Figure 3a). The proportion of all subjects with Vit D deficiencywas not significantly different between the cases and controls in men (Figure $3 \mathrm{~b}$ ). However, females with $\mathrm{CU}$ had predominantly lower levels of Vit $\mathrm{D}(17 \cdot 7 \pm 1 \cdot 12 \mathrm{ng} / \mathrm{ml})$ compared to controls $(25 \cdot 44 \pm 2 \cdot 24 \mathrm{ng} / \mathrm{ml}) \quad(* * \mathrm{P}=0$. 0018) (Figure 3b). Also women showed significantly lower levels of Vit $\mathrm{D}$ in comparison to men with $\mathrm{CU}(\mathrm{P}=0.0019)$ (Figure $3 \mathrm{~b})[27,28]$. Autologous serum skin test (ASST) results were positive in $58 \cdot 2 \%$ of the patients with $\mathrm{CU}$.

\section{Treatment response}

Effect of vitamin $D$ supplementation on serum $25(\mathrm{OH})_{2} D$ levels At enrollment, there was no significant difference in total baseline Vit D levels between subgroups a, b and c (Figure 3c). After 6 weeks of treatment, subgroup a undergoing Vit $\mathrm{D}$ supplementation alone showed a 3.3 fold increase in serum $25(\mathrm{OH})_{2} \mathrm{D}$ from $16.98 \pm$ $1.43 \mathrm{ng} / \mathrm{ml}$ to $56.74 \pm 3.76 \mathrm{ng} / \mathrm{ml}$ (Mean $\pm \mathrm{SEM}$ ) with $\because * \mathrm{P}<0.0001$ (Figure 3c). There was no significant change in $25(\mathrm{OH})_{2}$ Dfrom $17.04 \pm 1.54 \mathrm{ng} / \mathrm{ml}$ to $16.44 \pm$ $1.50 \mathrm{ng} / \mathrm{ml}$ in subgroup b (Figure 3c). In subgroup $\mathbf{c}$ 


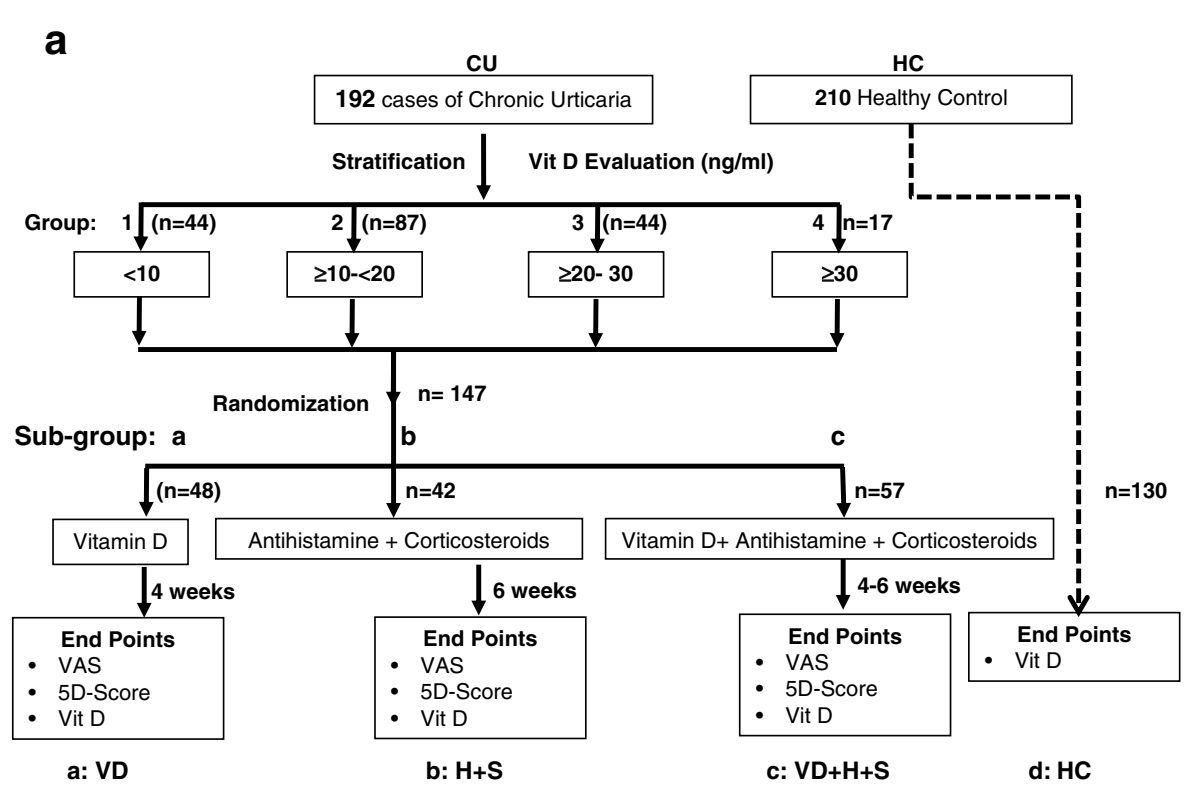

CU: Chronic Uriticaria; HC: Heathy Controls; VD: Vitamin D; H+D: Antihistamine + Corticosteroids; VD+H+D: Vitamin D + Antihistamine + Corticosteroids.

b

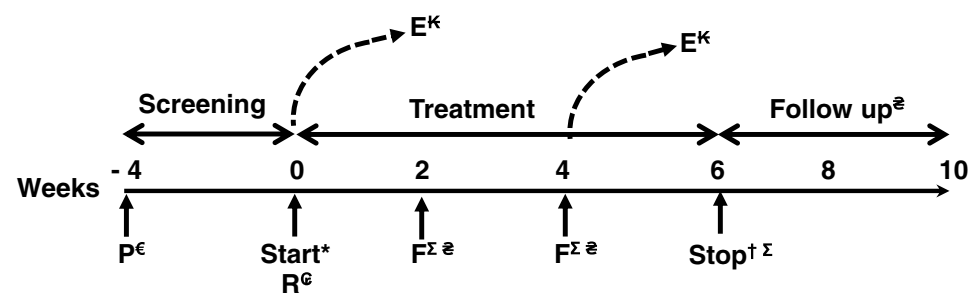

$€$ Persistent symptoms lasting $>6$ weeks

${ }^{\complement}$ Randomization into 3 groups

* Treatment started, Vitamin D evaluation, VAS \&5D score assessed

$\Sigma$ Follow up evaluation/ visits

†Treatment Stopped

* Patients excluded (not filling the eligibility criteria and/or developing secondary symptoms

z Safety Assessment/ Check for any adverse events

Figure 2 Experimental protocols. a. Vitamin $D$ evaluation and treatment regimen of Chronic Urticaria patients. Patients were stratified into 4 groups depending upon VitD levels. Group 1, 2, 3 and 4 consisted of patients with serum $25(\mathrm{OH})_{2} \mathrm{D}$ levels $<10 \mathrm{ng} / \mathrm{ml}, \geq 10 \mathrm{ng} /$ $\mathrm{ml}$ to $<20 \mathrm{ng} / \mathrm{ml}$, $\geq 20$ to $30 \mathrm{ng} / \mathrm{ml}$ and $>30 \mathrm{ng} / \mathrm{ml}$ respectively. All the groups were further randomized into 3 treatment protocol regimens, $a, b$ and c. 48 Patients in Protocol a received Vitamin D (VD) for 4 weeks, 42 patients in group $\mathbf{b}$ received antihistamines and corticosteroids $(\mathrm{H}+\mathrm{S})$ for 6 weeks and 57 patients in group c received a combinatorial therapy of vitamin (4 weeks) + antihistamines+ corticosteroids $(\mathrm{VD}+\mathrm{H}+\mathrm{S})$ for 6 weeks. 130 healthy controls $(\mathrm{HC})$ in group $\mathbf{d}$ were followed as such without any intervention. Patients were tested for Vit D, VAS and 5D score at the baseline and after 6 weeks of treatment. $\mathbf{b}$. Outline of experiment starting from recruitment to attaining the end point. Participants were screened for eligibility starting 4 weeks before the start of the experiment (Screening). The patients that do not fill the eligibility criteria and/or developed secondary disorders during the treatment were excluded from this study $\left(E^{K}\right)$. Follow up visit for safety assessment was at 2,4,6,8 and 10 weeks after the start of the study $\left(F^{z}\right)$. The treatment lasted for 6 weeks with follow up and safety assessment for another 4 weeks. The sample size calculations was chosen in a way that the test for the primary end point, the mean weekly VAS and 5-D score, would have $85 \%$ power by using a 2-sided 5\% significance level of the treatment effect (i.e., the difference between the treatment groups) was at least as large as its SD (standardized effect size, $>1$ ). 

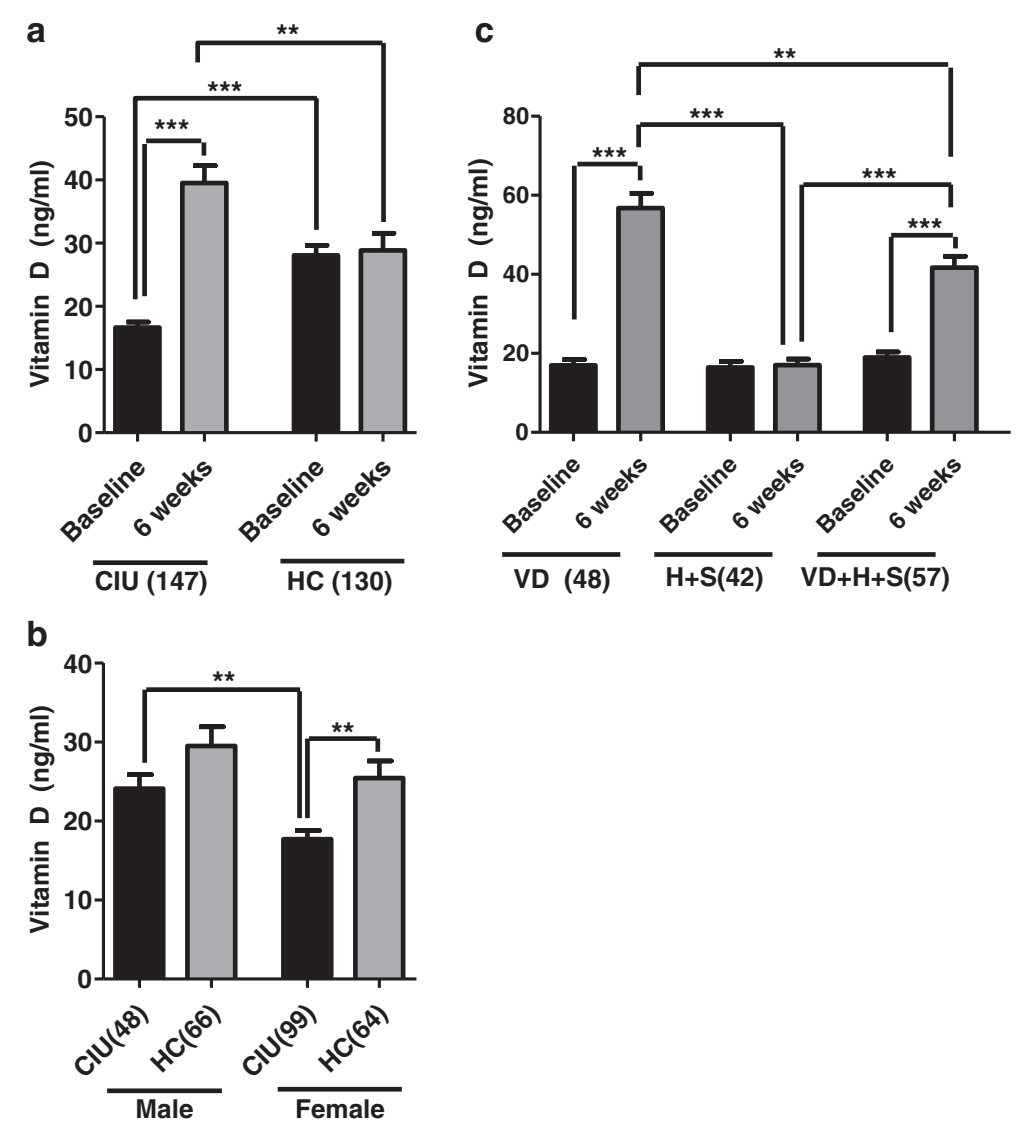

Figure 3 Vit D status in CU patients and healthy controls at baseline and after 6 weeks of treatment. a. Quantification of serum $25(\mathrm{OH})_{2} \mathrm{D}$ levels in CU patients and healthy controls at baseline and after 6 weeks of treatment. Data represents 147 CU patients and 130 healthy controls. Error bars represent SEM. Paired $t$-test was used to calculate the difference within groups and Bonferroni independent samples $t$-test was used to calculate the level of difference between groups. ${ }^{* *} \mathrm{P}<0.01$ and ${ }^{* * *} \mathrm{P}<0.0001$. b. Comparative analysis of baselineVit $\mathrm{D}$ levels in male and female CU patients and healthy controls. Error bars represent SEM. Number of patients in each group is represented in parentheses. ${ }^{* *} \mathrm{P}<0.01$. c. Serum $25(\mathrm{OH})_{2} \mathrm{D}$ levels in $\mathrm{CU}$ patients undergoing treatment under three regimens at baseline and after 6 weeks of treatment. Patients were treated with protocols VD, H+S and VD + H + Sand serum Vit D was measured at baseline and after 6 weeks. Paired t-test was used to calculate the difference within groups. Error bars represent SEM. ${ }^{* * P}<0.01 ;{ }^{* *} \mathrm{P}<0.0001$.

$(\mathrm{VD}+\mathrm{H}+\mathrm{S})$, there was 2.2 fold increase in total serum $25(\mathrm{OH})_{2} \mathrm{D}$ levels from $18.95 \pm 1.42 \mathrm{ng} / \mathrm{ml}$ to $41.73 \pm$ $2.85 \mathrm{ng} / \mathrm{ml}(* * * \mathrm{P}<0 \cdot 0001)$ (Figure 3c).

Subgroup a showed a significant increase in the serum $25(\mathrm{OH})_{2} \mathrm{D}$ levels across all the four groups 1-4 (Figure 4a). Group 1,2, 3 and 4 had a baseline $25(\mathrm{OH})_{2} \mathrm{D}$ levels of (Mean \pm SEM ng/ml) $4.89 \pm 1.2,14.96 \pm 0.57$, $23.46 \pm 0.93$ and $38.95 \pm 4.03$ which increased to $24.91 \pm$ $0.97(\mathrm{P}<0.0001), 57.49 \pm 3.07(\mathrm{P}<0.0001), 77.02 \pm 9.29$ $(\mathrm{P}=0.0001)$ and $71.39 \pm 2.44(\mathrm{P}=0.0006)$ respectively (Figure 4a). In subgroup a the patients having critically low levels of serum $25(\mathrm{OH})_{2} \mathrm{D}$ before treatment, showed a 5 fold increase after 6 weeks of treatment. Group 2 having deficient levels of serum $25(\mathrm{OH})_{2} \mathrm{D}$ showed almost 4 fold increase with serum $25(\mathrm{OH})_{2} \mathrm{D}$ levels attaining sufficiency. Similarly group 3 having insufficient levels of serum $25(\mathrm{OH})_{2} \mathrm{D}$ showed 3 fold increase and attained sufficiency. The patients already having sufficient levels of serum $25(\mathrm{OH})_{2} \mathrm{D}$ also showed less than 2 fold increase.

There was no significant change in all the four groups $1-4$ in subgroup b (Mean \pm SEM ng/ml) $5.642 \pm$ $1.4,14.69 \pm 0.43,26.54 \pm 1.3$ and $38.21 \pm 1.42)$ when compared to baseline $25(\mathrm{OH})_{2}$ D serum levels $(5.141 \pm 1.23$, $14.71 \pm 0.55,24.36 \pm 1.00$ and $38.58 \pm 4.38$ ) respectively (Figure 4b). In subgroup b the patients did not show any significant change in any of the 4 groups as expected.

Subgroup c also showed a significant increase in serum $25(\mathrm{OH})_{2} \mathrm{D}$ levels in group 1, 2 and 3 (Figure $4 \mathrm{c}$ ). The serum $25(\mathrm{OH})_{2} \mathrm{D}$ levels increased from baseline $4.987 \pm 0.97$, $14.53 \pm 0.59$ and $24.28 \pm 0.66$ to $18.69 \pm 2.12(\mathrm{P}<0.0001)$, $53.10 \pm 4.81(\mathrm{P}<0.0001)$ and $41.92 \pm 5.06 \quad(\mathrm{P}=0.0043)$ respectively. However, group 4 did not show any significant increases from baseline $37.22 \pm 2.38$ to $44.56 \pm 2.67$ at week 6 (Figure 4c). In subgroup $\mathbf{c}$ the patients having 


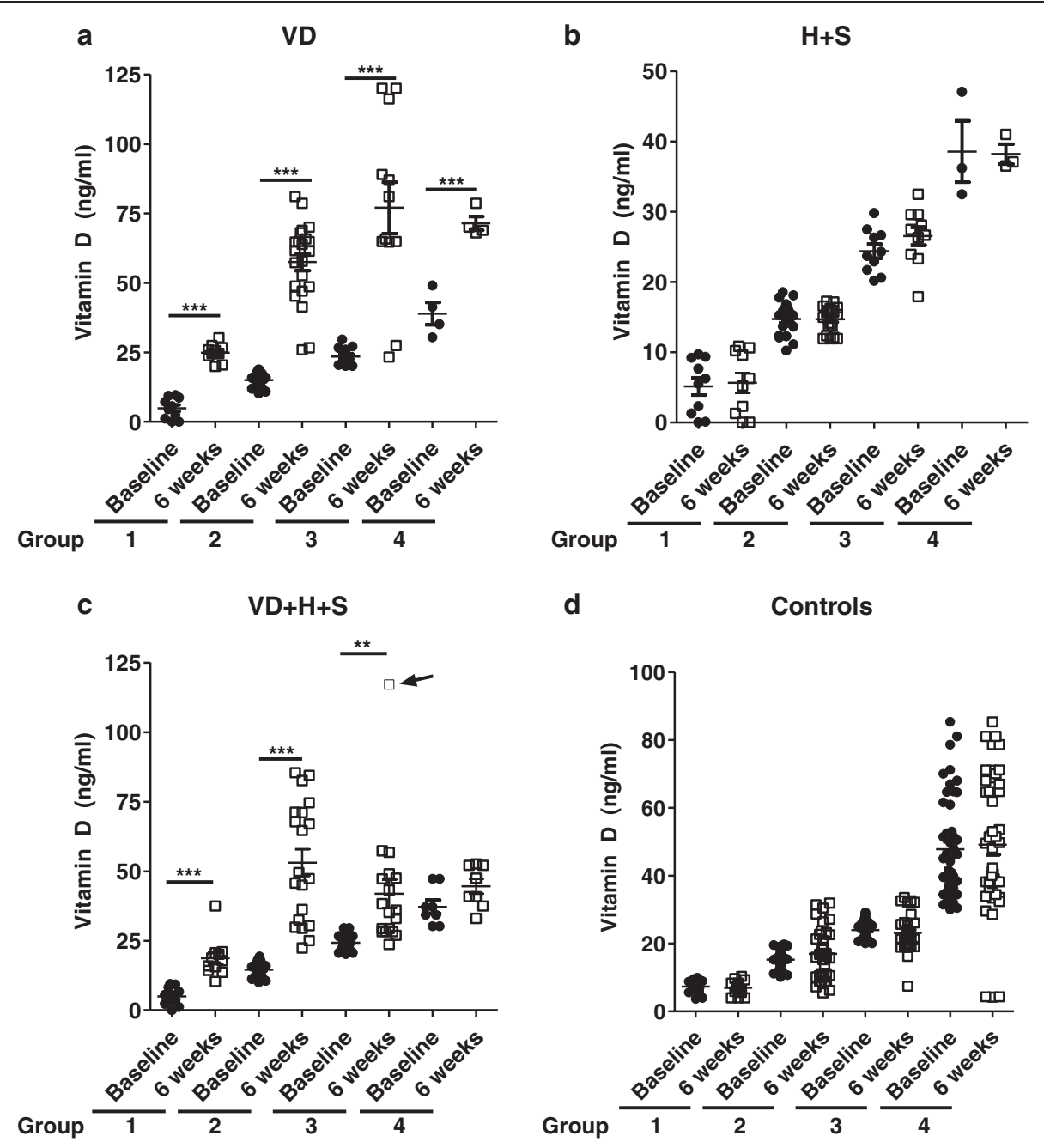

Figure 4 Serum $25(\mathrm{OH})_{2} \mathrm{D}$ levels in $\mathrm{CU}$ patients undergoing treatment under three treatment regimens at baseline and after 6 weeks of treatment. a. Patients were treated with protocols VD and serum Vit D was measured at baseline and after 6 weeks. Paired t-test was used to calculate the difference within groups. Error bars represent SEM. ${ }^{* * *} \mathrm{P}<0.0001$. b. Patients were treated with protocols $\mathrm{H}+\mathrm{S}$ and serum Vit $\mathrm{D}$ was measured at baseline and after 6 weeks of treatment. c. Patients were treated with protocols VD $+\mathrm{H}+\mathrm{S}$ and serum Vit D was measured at baseline and after 6 weeks of treatment. The arrow depicts the patient that developed hypercalcemia. $\mathbf{d}$. Vit $\mathrm{D}$ levels in controls subjects. Paired $t$-test was used to calculate the difference within groups. Error bars represent SEM. ${ }^{* *} \mathrm{P}<0.01$; ${ }^{* * *} \mathrm{P}<0.0001$. Vitamin $\mathrm{D}(\mathrm{VD})$, Hydroxizine (H) and Deflazacort (S).

critically low levels of serum $25(\mathrm{OH})_{2} \mathrm{D}$ before treatment, showed a 3.7 fold increase after 6 weeks of treatment. Group 2 having deficient levels of serum 25 $(\mathrm{OH})_{2} \mathrm{D}$ showed 3.6 fold increase with serum $25(\mathrm{OH})$ ${ }_{2} \mathrm{D}$ levels attaining sufficiency. Group 3 having insufficient levels of serum $25(\mathrm{OH})_{2} \mathrm{D}$ showed less than 2 fold increase and attained sufficiency. However the change was not significant when compared to group 3 of subgroup a. One patient in group 3 subgroup c showed an elevated vitamin $\mathrm{D}$ after 4 weeks of treatment with combinatorial therapy. The patient when evaluated for for basic biochemistry showed an elevated serum calcium levels. After stopping the treatment the patient retained normal calcium levels in less than 2 days. In this time the patent was monitored continuously.

Healthy Control group did not show any significant change in all the four groups with serum $25(\mathrm{OH})_{2}$ D levels at baseline $(7.310 \pm 0.52,15.26 \pm 0.47,23.98 \pm 0.46$ and $47.78 \pm 2.23)$ to $(5.899 \pm 0.28,16.96 \pm 1.26,23.15 \pm 0.95$ and $49.18 \pm 2.97$ ) (Figure $4 \mathrm{~d}$ ). All the groups of control subgroup d did not show any change in serum $25(\mathrm{OH})_{2} \mathrm{D}$ levels as expected.

Moreover, no adverse effects were observed in the study subjects after two, four and six weeks of treatment except for one patient that developed hypercalcemia in subgroup c $(\mathrm{VD}+\mathrm{H}+\mathrm{S})$ and was withdrawn from the study. 


\section{VAS score}

The mean VAS score in subgroupadecreased significantly from a baseline score of $6 \cdot 7 \pm 0 \cdot 043$ to the score of $5 \cdot 2 \pm 0 \cdot 70$ with ${ }^{*} \mathrm{P}=0 \cdot 0088$ (Figure $5 \mathrm{a}$ ). The mean VAS score of subgroup $\mathbf{b}$ was significantly reduced to half from $6.6 \pm 0.42$ at baseline to $3 \cdot 3 \pm 0.50$ with ${ }^{* * *} \mathrm{P}<0.0001$ (Figure 5a). Similarly the mean VAS score in subgroup cwas reduced significantly by 3.6 fold from baseline $6 \cdot 68 \pm 0 \cdot 40$ to $1 \cdot 86 \pm 0 \cdot 39$ with $^{* * *} \mathrm{P}<0 \cdot 0001$ (Figure 5a). Comparing inter group VAS score there was a significant differencein subgroup b compared to subgroup a ${ }^{*} \mathrm{P}=0$. 0106) at week 6. Subgroup a also showed a significant difference in VAS when compared to the subgroup c $\left({ }^{* * *} \mathrm{P}<0.0001\right)$, VAS score in subgroup calso showed a significant differencein comparison to subgroup $\mathbf{b}$ with ${ }^{*} \mathrm{P}=0 \cdot 0203$ (Figure 5a).

\section{5-D itch score}

The mean 5-D itch score in subgroup adecreased significantly from a baseline score of $14 \cdot 5 \pm 0 \cdot 72$ to the score of $12 \cdot 06 \pm 1 \cdot 10$ with ${ }^{* *} \mathrm{P}=0 \cdot 0072$ (Figure $5 \mathrm{~b}$ ). The mean 5 -D score of subgroup b was significantly reduced to half from $13 \cdot 9 \pm 0 \cdot 77$ at baseline to $8 \cdot 1 \pm 1 \cdot 13$ with $* * \mathrm{P}<0.0001$ (Figure 5b). Similarly the mean 5-D score in subgroup c was reduced significantly by 2.8 fold from $13 \cdot 9 \pm 0 \cdot 68$ to $5 \cdot 01 \pm 0.94$ with $* * \mathrm{P}<0$. 0001(Figure 5b).

Comparing inter subgroup 5-D score there was a significant difference in subgroup $\mathbf{b}$ compared to subgroup a $(* \mathrm{P}=0.0116)$. Subgroup a also showed a significant difference in 5-D score when compared to the group c $(* * * \mathrm{P}<0 \cdot 0001) .5-\mathrm{D}$ score in subgroup $\mathbf{c}$ also showed a significant difference in comparison to subgroup $\mathbf{b}$ with ${ }^{*} \mathrm{P}=0 \cdot 0382$ (Figure 5b).

\section{Discussion}

$\mathrm{CU}$ encompasses a heterogeneous group of disorders with diverse underlying etiologies. However, upto $40 \%$ of patients with $\mathrm{CU}$ are autoimmune in nature, demonstrate auto antibodies against either high-affinity IgE receptors (FcERI subunit) or IgE antibody on mast cell surfaces[3]. Degranulation of mast cells with release of histamine is central to the pathogenesis of urticaria[29]. $\mathrm{H} 1$ antagonists are firmly established as first line therapy for CU with adjunctive support from medications of other classes, such as antileukotrienes, immunosuppressive and anti-inflammatory agents (including steroids and cyclosporine) [30],[31]. Vit D has anti-inflammatory properties, as observed by the $1,25(\mathrm{OH}) 2 \mathrm{D}$ mediated reduction of dendritic cell (DC) maturation [32]. Furthermore, Vit D contributes to the conversion of CD4+ $\mathrm{T}$ cells to $\mathrm{T}$ regulatory cells, which have been shown to play a role in the suppression of pro-allergic mechanisms[33].
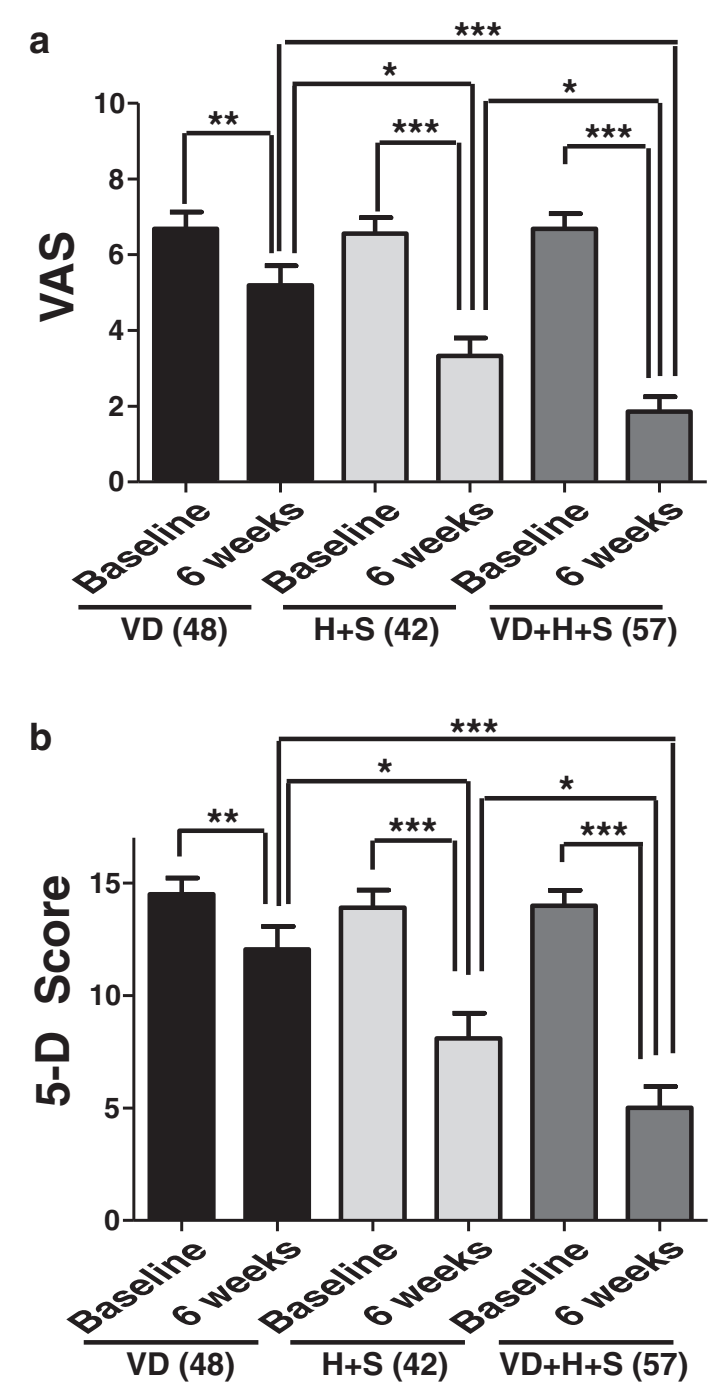

Figure 5 Effect of Vitamin D supplementation in different therapy protocols for CU: a. Effect of Vitamin D (VD), antihistamines $(H)$ and corticosteroids (S) on VAS of CU patients. Patients were treated with VD alone, $\mathrm{H}+\mathrm{S}$ and $\mathrm{VD}+\mathrm{H}+\mathrm{S}$ for 6 weeks. VAS was calculated at the start of the study (baseline) and after 6 weeks of treatment. Values are presented as mean \pm SEM. ${ }^{*}, \mathrm{P}<0.05$; ${ }^{* *}, \mathrm{P}<0.01 ;{ }^{* *}, \mathrm{P}<0.0001$.

Number of patients in each group is represented in parentheses. b. Effect of Vitamin D (VD), antihistamines(H) and corticosteroids (S) on 5-D score of CU patients. Patients were treated with VD alone, $\mathrm{H}+\mathrm{S}$ and $\mathrm{VD}+\mathrm{H}+\mathrm{S}$ for 6 weeks. $5-\mathrm{D}$ score was calculated at the start of the study (baseline) and after 6 weeks of treatment. Number of patients in each group is represented in parentheses. Values are presented as mean \pm SEM. ${ }^{*}, \mathrm{P}<0.05 ;{ }^{* *}, \mathrm{P}<0.01 ;{ }^{* * *}, \mathrm{P}<0.0001$. The primary end point (VAS and 5D-Score) was evaluated by using an analysis of covariance model with the factors of treatment and center and with the baseline score as the covariate. For the treatment contrast between the three groups a, b and c, a 95\% Cl and a 2-sided P value were calculated. Mean score (VAS, 5-D) changes within group VD and group $\mathrm{H}+\mathrm{S}$ and group $\mathrm{VD}+\mathrm{H}+\mathrm{S}$ were compared, using paired $t$-test (keeping normality of the observation into considerations). Intergroup comparison at different time-points was done using analysis of variance test (ANOVA). A $P<0.05$ was taken to be statistically significant. 
Vit D deficiency is presently a major health problem in both adults and children across the globe and highly prevalent in Indian sub-continent $[8,34,35]$. The study population was predominately ethnic, consistent with the region and had Vit $\mathrm{D}_{3}$ insufficiency or deficiency. We devised a randomized study to evaluate whether correcting hypovitaminosis D had any therapeutic effectiveness on CU. Theprimary objective of our study was to ascertain a potential link between $V i t \mathrm{D}_{3}$ deficiency and $\mathrm{CU}$ and the effect of $\mathrm{VitD}_{3}$ supplementation in repressing the symptoms of CU. A high percent (91.3\%) of CU patients had insufficient or deficient $25(\mathrm{OH})_{2} \mathrm{D}$ levels against $63.8 \%$ of the healthy control participants, suggesting a possible role of Vit $\mathrm{D}_{3}$ deficiency in the pathogenesis and exacerbation of $\mathrm{CU}$. These findings provide a detailed investigation of the beneficial effect of Vit $D_{3}$ supplementation in $\mathrm{CU}$ patients. The present investigation further support and are consistent with the previous studythat showed $\mathrm{CU}$ patients have significantly low levels of $25(\mathrm{OH})_{2} \mathrm{D}[16]$ and Vit $\mathrm{D}_{3}$ supplementation decreases the $\mathrm{CU}$ symptoms and increases the quality of life of the patients diagnosed with $\mathrm{CU}$ [22].

A high dose of Vit $\mathrm{D}_{3}(60,000 \mathrm{IU} /$ week for4weeks) was used in the present study because there is high prevalence of Vit $\mathrm{D}_{3}$ deficiency and/or insufficiency in the Kashmiri population[8] and beneficial effect of high dose of Vit $\mathrm{D}_{3}$ over low dose in the treatment and recovery of patients with $\mathrm{CU}$ has been reported recently[22]. The notion behind using Vit $D_{3}$ instead of Vit $D_{2}$ in the present investigation was that Vit D3 is more potent for raising and maintaining steady-state $25(\mathrm{OH})_{2} \mathrm{D}$ levels than VitD2 $[34,36]$.

$\mathrm{CU}$ is intractable skin disease, antihistamines and systemic steroids form the basis of treatment, but response is often incomplete [4]. An association of pruritus, rash, and urticaria/ angioedema with low $25(\mathrm{OH})_{2} \mathrm{D}<32 \mathrm{ng} / \mathrm{mlhas}$ also been reported,andresolution of symptoms following Vit $D_{3}$ replacement was observed in $70 \%$ of those patients with cutaneous symptoms and concurrent Vit $\mathrm{D}_{3}$ deficiency [20], however no detailed extensive study has beenreported so far on the efficacy of Vit $\mathrm{D}_{3}$ supplementation in resolving the symptoms of $\mathrm{CU}$. In the present investigation we observed the patients that receivedVit $D_{3}$ as monotherapy showed improvement in the CU symptoms. The patients that received combinatorial therapy showed better improvement of symptoms and quality of life than the patients who received only standard therapeutic regimen [37].

Although the patients receiving Vit $\mathrm{D}_{3}$ alone and the patients receiving standard treatment with Vit $\mathrm{D}_{3}$ supplementation received equal amount of $\mathrm{Vit}_{3}$, there was still a significant difference in the serum $25(\mathrm{OH})_{2} \mathrm{D}$ levels between these twosubgroups, with subgroup a showing significantly higher levels of $\mathrm{Vit}_{3}$ then subgroup c. This difference can be attributed to the effect of systemic corticosteroids on the $25(\mathrm{OH})_{2} \mathrm{D}$ levels [38].
Althoughthe course of $\mathrm{CU}$ is often quite variable and protracted;a short follow-up of just 6 week was enough to show a significant effect on Vit D, VAS and 5-D score. Furthermore, the patients with $\mathrm{CU}$ who exhibit incomplete response to drug therapy continue to have symptoms, although there might be a reduction in their symptoms. For this reason, the VAS and 5D-itch scoresare likely more reliable indicators of treatment response in short duration studies.

In view of present study, role of Vit $\mathrm{D}_{3}$ alone as treatment for $\mathrm{CU}$ seems conclusive, although combinatorial therapy proved more effective form of treatment in patients with $\mathrm{CU}$. The exact underlying mechanism needs still to be investigated even though the possible reason might be adjunctive action from different classes of drugs in diverse pathogenesis of CU.

\section{Conclusions}

Our study showed Vit $\mathrm{D}_{3}$ levels are significantly reduced in subjects with $\mathrm{CU}$ compared with controls. The study provides a rationale for the selection of Vit D supplementation as "add-on" therapy for the treatment of CU with patients showing a greater resolution of CU symptoms.

\section{Abbreviations \\ CU: Chronic Urticaria; ASST: Autologous serum skin testing; VAS: Visual analogue scale; VDRs: Vitamin D receptors; VD: Vitamin D.}

\section{Competing interests}

The authors declare that they have no competing interests.

\section{Authors' contributions}

RR- Contributed substantially to conception, design and acquisition of data, revised the manuscript critically for important intellectual content. KZM, IAS \& QY - Contributed substantially to conception, design, acquisition of data, analyzed the data, drafted and revised the manuscript., IAB, IQ, SN, ZASHelped in the analysis and interpretation of the data, helped in drafting the manuscript and revised the manuscript critically for important intellectual content. All the authors finally approved the final version of the manuscript to be published.

\section{Acknowledgment}

This project used the departmental Facility and was supported in part by departmental financialGrant 2012-14.

\section{Author details}

${ }^{1}$ Department of Immunology and Molecular Medicine, Sher-i- Kashmir Institute of Medical Sciences, Soura, Srinagar, J\&K 190011, India. ${ }^{2}$ Division of Biotechnology, Sher-e-Kashmir University of Agricultural Sciences and Technology of Kashmir, Srinagar, J\&K 190025, India.

Received: 22 December 2014 Accepted: 23 March 2015

Published online: 04 June 2015

\section{References}

1. Shear S. Andrews' diseases of the skin: Clinical dermatology. JAMA. 2012;307:92

2. Ortonne JP. Chronic urticaria: a comparison of management guidelines. Expert Opin Pharmacother. 2011;12:2683-93.

3. Losol P, Yoo HS, Park HS. Molecular genetic mechanisms of chronic urticaria. Allergy, asthma \& immunology research. 2014;6:13-21.

4. Sanchez-Borges M, Asero R, Ansotegui IJ, Baiardini I, Bernstein JA, Canonica GW, et al. Diagnosis and treatment of urticaria and angioedema: a worldwide perspective. The World Allergy Organization journal. 2012;5:125-47. 
5. Grattan CE, O'Donnell BF, Francis DM, Niimi N, Barlow RJ, Seed PT, et al. Randomized double-blind study of cyclosporin in chronic 'idiopathic' urticaria. Br J Dermatol. 2000;143:365-72.

6. Maurer M, Rosen K, Hsieh HJ, Saini S, Grattan C, Gimenez-Arnau A, et al. Omalizumab for the treatment of chronic idiopathic or spontaneous urticaria. N Engl J Med. 2013;368:924-35.

7. Zuberbier T, Asero R, Bindslev-Jensen C, Walter Canonica G, Church MK, Gimenez-Arnau AM, et al. EAACI/GA(2)LEN/EDF/WAO guideline: management of urticaria. Allergy. 2009;64:1427-43.

8. Zargar AH, Ahmad S, Masoodi SR, Wani Al, Bashir Ml, Laway BA, et al. Vitamin D status in apparently healthy adults in Kashmir Valley of Indian subcontinent. Postgrad Med J. 2007;83:713-6.

9. Oren E, Banerji A, Camargo Jr CA. Vitamin D and atopic disorders in an obese population screened for vitamin D deficiency. J Allergy Clin Immunol. 2008;121:533-4.

10. Sharief S, Jariwala S, Kumar J, Muntner P, Melamed ML. Vitamin D levels and food and environmental allergies in the United States: results from the National Health and Nutrition Examination Survey 2005-2006. J Allergy Clin Immunol. 2011;127:1195-202

11. Arshi S, Ghalehbaghi B, Kamrava SK, Aminlou M. Vitamin D serum levels in allergic rhinitis: any difference from normal population? Asia Pacific allergy. 2012;2:45-8

12. Welsh J. Targets of vitamin D receptor signaling in the mammary gland Journal of bone and mineral research : the official journal of the American Society for Bone and Mineral Research. 2007;22(2):V86-90.

13. Prietl B, Treiber G, Pieber TR, Amrein K. Vitamin D and immune function. Nutrients. 2013:5:2502-21.

14. Jones AP, Tulic MK, Rueter K, Prescott SL. Vitamin D and Allergic Disease: Sunlight at the End of the Tunnel? Nutrients. 2011;4:13-28.

15. Miller J, Gallo RL. Vitamin D and innate immunity. Dermatol Ther. 2010;23:13-22.

16. Thorp WA, Goldner W, Meza J, Poole JA. Reduced vitamin D levels in adult subjects with chronic urticaria. J Allergy Clin Immunol. 2010;126:413. author reply $413-414$

17. Rorie A, Goldner WS, Lyden E, Poole JA. Beneficial role for supplemental vitamin D3 treatment in chronic urticaria: a randomized study. Annals of allergy, asthma \& immunology : official publication of the American College of Allergy, Asthma, \& Immunology. 2014;112:376-382.

18. Mason AR, Mason J, Cork M, Dooley G, Hancock H. Topical treatments for chronic plaque psoriasis. The Cochrane database of systematic reviews. 2013;3:CD005028.

19. Wacker M, Holick MF. Vitamin D - effects on skeletal and extraskeletal health and the need for supplementation. Nutrients. 2013:5:111-48.

20. Goetz DW. Idiopathic itch, rash, and urticaria/angioedema merit serum vitamin D evaluation: a descriptive case series. W V Med J. 2011;107:14-20.

21. Holick MF, Chen TC. Vitamin D deficiency: a worldwide problem with health consequences. Am J Clin Nutr. 2008;87:1080S-6S.

22. Rorie A, Goldner WS, Lyden E, Poole JA: Beneficial role for supplemental vitamin $D$ treatment in chronic urticaria: a randomized study. Annals of allergy, asthma \& immunology: official publication of the American College of Allergy, Asthma, \& Immunology 2014;112:376-382

23. Zuberbier T, Asero R, Bindslev-Jensen C, Walter Canonica G, Church MK, Gimenez-Arnau A, et al. EAACI/GA(2)LEN/EDF/WAO guideline: definition, classification and diagnosis of urticaria. Allergy. 2009;64:1417-26.

24. Maurer M, Altrichter S, Bieber T, Biedermann T, Brautigam M, Seyfried S, et al. Efficacy and safety of omalizumab in patients with chronic urticaria who exhibit IgE against thyroperoxidase. J Allergy Clin Immunol. 2011;128:202-9.

25. Elman S, Hynan LS, Gabriel V, Mayo MJ. The 5-D itch scale: a new measure of pruritus. Br J Dermatol. 2010;162:587-93.

26. Reich A, Heisig M, Phan NQ, Taneda K, Takamori K, Takeuchi S, et al. Visual analogue scale: evaluation of the instrument for the assessment of pruritus. Acta Derm Venereol. 2012;92:497-501

27. Thacher TD, Clarke BL. Vitamin D insufficiency. Mayo Clinic proceedings Mayo Clinic. 2011:86:50-60

28. Rosen CJ. Clinical practice. Vitamin D insufficiency. N Engl J Med. 2011;364:248-54

29. Kaplan AP. Chronic urticaria: pathogenesis and treatment. J Allergy Clin Immunol. 2004;114:465-74. quiz 475.

30. Khan DA. Alternative Agents in Refractory Chronic Urticaria: Evidence and Considerations on Their Selection and Use. Journal of Allergy and Clinical Immunology: In Practice. 2013;1:433-40. e431.
31. Adelman DC, Casale TB, Corren J (eds) Manual of Allergy and Immunology Diagnosis and Therapy. $4^{\text {th }}$ Edition Lippincott Williams \& Wilkins 2002.

32. Bikle DD. Vitamin D and immune function: understanding common pathways. Curr Osteoporos Rep. 2009;7:58-63.

33. Vassallo MF, Camargo Jr CA. Potential mechanisms for the hypothesized link between sunshine, vitamin $\mathrm{D}$, and food allergy in children. J Allergy Clin Immunol. 2010;126:217-22.

34. Holick MF. Vitamin D deficiency. N Engl J Med. 2007;357:266-81.

35. Ramakrishnan S, Bhansali A, Bhadada SK, Sharma R, Walia R, Ravikiran M, et al. Vitamin D status and its seasonal variability in healthy young adults in an Asian Indian urban population. Endocrine practice : official journal of the American College of Endocrinology and the American Association of Clinical Endocrinologists. 2011;17:185-91.

36. Tripkovic L, Lambert H, Hart K, Smith CP, Bucca G, Penson S, et al. Comparison of vitamin D2 and vitamin D3 supplementation in raising serum 25-hydroxyvitamin D status: a systematic review and meta-analysis. Am J Clin Nutr. 2012;95:1357-64.

37. Chren MM, Lasek RJ, Flocke SA, Zyzanski SJ. Improved discriminative and evaluative capability of a refined version of Skindex, a quality-of-life instrument for patients with skin diseases. Arch Dermatol. 1997;133:1433-40.

38. Skversky AL, Kumar J, Abramowitz MK, Kaskel FJ, Melamed ML. Association of glucocorticoid use and low 25-hydroxyvitamin D levels: results from the National Health and Nutrition Examination Survey (NHANES): 2001-2006. J Clin Endocrinol Metab. 2011;96:3838-45.

\section{Submit your next manuscript to BioMed Central and take full advantage of:}

- Convenient online submission

- Thorough peer review

- No space constraints or color figure charges

- Immediate publication on acceptance

- Inclusion in PubMed, CAS, Scopus and Google Scholar

- Research which is freely available for redistribution 